\title{
Solubility of Anthracene in Ternary Methyl tert-Butyl Ether + Alcohol + Cyclohexane Solvent Mixtures at 298.15 K
}

\author{
Karen J . Pribyla, Michael A. Spurgin, I vette Chuca, and William E. Acree, J r.*
}

Department of Chemistry, University of North Texas, Denton, Texas 76203-5070

\begin{abstract}
Experimental solubilities are reported for anthracene dissolved in ternary methyl tert-butyl ether + 1-propanol + cyclohexane, methyl tert-butyl ether + 2-propanol + cyclohexane, methyl tert-butyl ether + 1-butanol + cyclohexane, methyl tert-butyl ether + 2-butanol + cyclohexane, and methyl tert-butyl ether + 2-methyl-1-propanol + cyclohexane solvent mixtures at $25^{\circ} \mathrm{C}$ and atmospheric pressure. Nineteen compositions were studied for each of the five solvent systems. Results of these measurements are used to test the predictive ability of the ternary solvent form of the combined NI MS/Redlich-Kister equation. Computations showed that the model predicted the observed solubility behavior to within an overall average absolute deviation of about $1.7 \%$, which is comparable to the experimental uncertainty of $\pm 1.5 \%$.
\end{abstract}

\section{Introduction}

Solid-liquid equilibrium data of organic nonelectrolyte systems are becoming increasingly important in the petroleum industry, particularly in light of present trends toward heavier feedstocks and the known carcinogenicity/ mutagenicity of many of the larger polycyclic aromatic compounds. Solubility data for a number of polycyclic aromatic hydrocarbons (i.e., anthracene and pyrene) and heteroatom polynuclear aromatics (i.e., carbazole, di benzothiophene, and xanthene) have been published in the recent chemical literature. For a listing of references, see Acree. ${ }^{1-3}$ Despite efforts by experimental ists and scientific organizations, both in terms of new experimental measurements and critically evaluated data compilations, there still exist numerous systems for which solubility data are not readily available.

In the present study anthracene solubilities have been measured in five ternary methyl tert-butyl ether + alcohol + cyd ohexane systems at $(25.0 \pm 0.1)^{\circ} \mathrm{C}$. Nineteen ternary compositions were studied for each of the five systems. Results of these measurements are used to test the predictive ability of expressions based upon the general mixing model used in deriving the combined NIBS/RedlichKister equation. Subsequent studies will interpret the measured anthracene solubilities using both mobile order theory and the Kretschmer-Wiebe association model. Powell et al. ${ }^{4}$ and $\mathrm{McH}$ ale et al. ${ }^{5}$ showed that these latter two solution models provided reasonably accurate descriptions for the solubility behavior of pyrene and anthracene in binary alkane + alcohol and alcohol + alcohol solvent mixtures. Neither model has been used to describe solubility in ternary solvent systems.

\section{Experimental Methods}

Anthracene (Aldrich, 99.9+\%) was used as received. 1-Propanol (Aldrich, 99+\%, anhydrous), 2-propanol (Aldrich, 99+\%, anhydrous), 1-butanol (Aldrich, HPLC, 99.8+\%), 2-butanol (Aldrich, 99+\%, anhydrous), 2-methyl-1-propanol (Aldrich, 99.5\%, anhydrous), cyclohexane (Aldrich, HPLC,

\footnotetext{
* To whom correspondence should be addressed. E-mail: acree@unt.edu.
} Fax: (940) 565-4318.
99.9+\%), and methyl tert-butyl ether (Arco, 99.9\%) were stored over molecular sieves and distilled shortly before use. Gas chromatographic analysis showed solvent purities to be $99.7 \mathrm{~mol} \%$ or better. Ternary solvent mixtures were prepared by mass so that compositions could be calculated to 0.0001 mole fraction. The methods of sample equilibration and spectrophotometric analysis are discussed in an earlier paper. ${ }^{6}$ Experimental anthracene solubilities in the five methyl tert-butyl ether + al cohol + cyclohexane solvent mixtures are listed in Table 1. Numerical values represent the average of between four and eight independent determinations, with the measured values being reproducible to within $\pm 1.5 \%$.

\section{Results and Discussion}

Acree and co-workers ${ }^{7-9}$ suggested the combined NIBS/ Redlich-Kister equation for the mathematical representation of isothermal solubility data in binary solvent systems

$$
\ln x_{A}^{s a t}=x_{B}^{\circ} \ln \left(x_{A}^{s a t}\right)_{B}+x_{C}^{\circ} \ln \left(x_{A}^{s a t}\right)_{C}+x_{B}^{\circ} x_{C}^{\circ} \sum_{i=0}^{n} S_{i}\left(x_{B}^{\circ}-x_{C}^{\circ}\right)^{i}
$$

where $x_{B}^{\circ}$ and $x_{C}^{\circ}$ refer to the initial mole fraction composition of the binary solvent calculated as if the solute were not present and $\left(x_{A}^{\text {sat }}\right)_{i}$ denotes the measured solute solubility in pure solvent $i$. The various $S_{i}$ curve-fit parameters can be evaluated with a least-squares analysis. For a ternary solvent system, the mathematical representation takes the form

$$
\begin{array}{r}
\ln x_{A}^{\text {sat }}=x_{B}^{\circ} \ln \left(x_{A}^{\text {sat }}\right)_{B}+x_{C}^{\circ} \ln \left(x_{A}^{\text {sat }}\right)_{C}+x_{D}^{\circ} \ln \left(x_{A}^{s a t}\right)_{D}+ \\
x_{B}^{\circ} x_{C}^{\circ} \sum_{i=0}^{r} S_{i, B C}\left(x_{B}^{\circ}-x_{C}^{\circ}\right)^{i}+x_{B}^{\circ} x_{D}^{\circ} \sum_{j=0}^{s} S_{j, B D}\left(x_{B}^{\circ}-x_{D}^{\circ}\right)^{j}+ \\
x_{C}^{\circ} x_{D}^{\circ} \sum_{k=0}^{t} S_{k, C D}\left(x_{C}^{\circ}-x_{D}^{\circ}\right)^{k}
\end{array}
$$

Recent studies have shown that eq 2 provides reasonably accurate predictions for anthracene solubilities in ternary two alkane + alcohol $^{10,11}$ and alkane + two alcohol ${ }^{12-14}$ 
Table 1. Experimental Mole Fraction Solubilities of Anthracene $\left(x_{A}^{\text {sat }}\right)$ in Ternary Methyl tert-Butyl Ether (B) + Alcohol (C) + Cyclohexane (D) Solvent Mixtures at 298.15 K

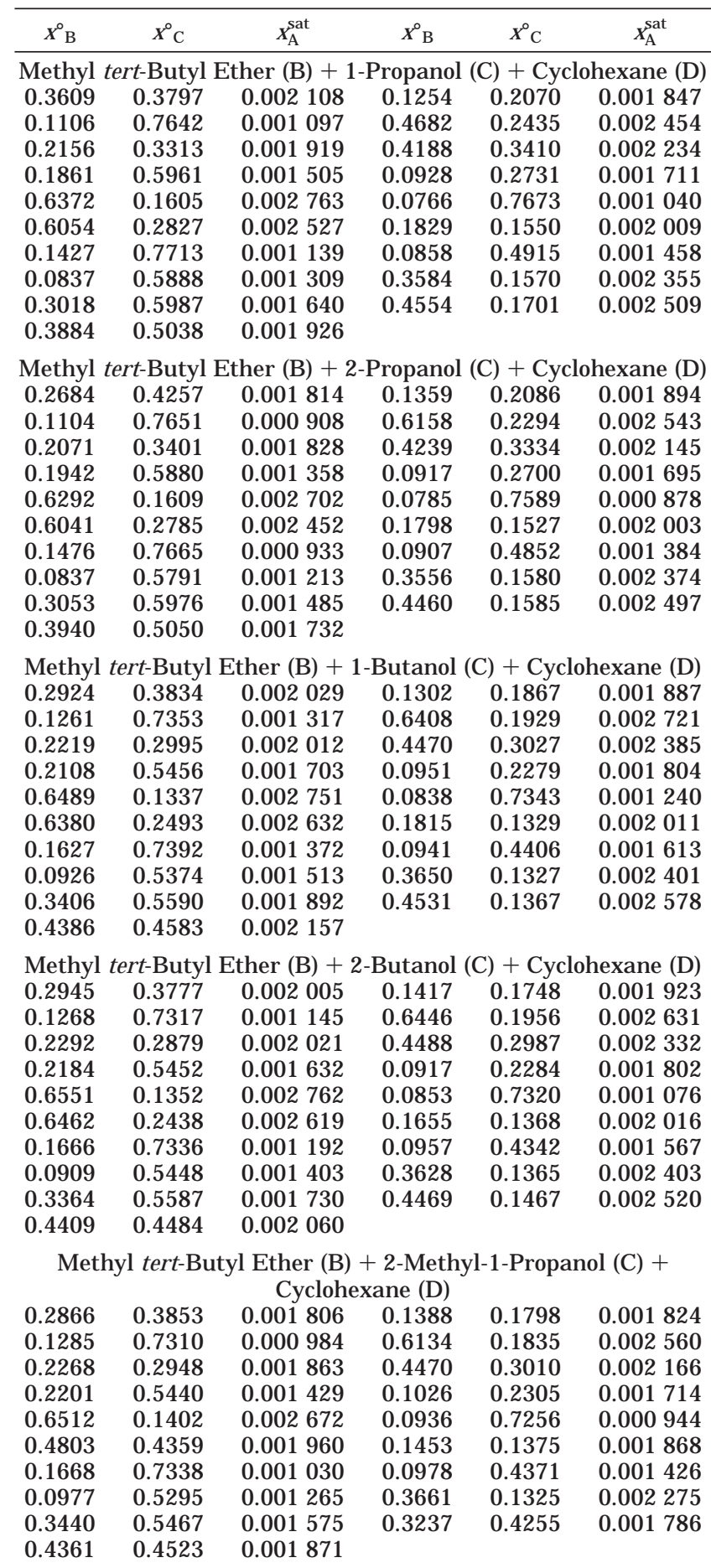

solvent mixtures. Such systems exhibit fairly large deviations from solution ideality arising from the self-association of each alcohol cosolvent, and, in mixtures containing two alcohol cosolvents, from the formation of heterogeneous hydrogen-bonded chains between dissimilar alcohol molecules.

The predictive ability of eq 2 is summarized in Table 3 for anthracene dissolved in the five methyl tert-butyl ether + alcohol + cyclohexane systems. Unlike the ternary two alkane + alcohol and alkane + two alcohol solvent mixtures studied previously, hydrogen-bond formation is terminated each time that an alcohol molecule hydrogen bonds with
Table 2. Combined NIBS/Redlich-Kister Parameters Calculated from Anthracene Solubilities in the Sub-binary Solvent Systems

\begin{tabular}{lr}
\hline solvent (B) + solvent (C) & \multicolumn{1}{c}{$\mathrm{S}^{\mathrm{a}}$} \\
\hline 2-methyl-1-propanol (B) + cycl ohexane (C) & 1.116 \\
& -0.172 \\
2-propanol (B) + cyclohexane (C) & 0.341 \\
& 1.589 \\
2-butanol (B) + cyclohexane (C) & 0.143 \\
& 0.248 \\
1-propanol (B) + cyclohexane (C) & 1.260 \\
& -0.206 \\
1-butanol (B) + cyclohexane (C) & 1.121 \\
& -0.040 \\
methyl tert-butyl ether (B) + 1-propanol (C) & 0.256 \\
& 0.741 \\
methyl tert-butyl ether (B) + 2-propanol (C) & -0.345 \\
& 0.223 \\
& 1.688 \\
methyl tert-butyl ether (B) + 1-butanol (C) & -0.283 \\
& 0.272 \\
& 1.976 \\
methyl tert-butyl ether (B) + 2-butanol (C) & -0.514 \\
& 0.651 \\
methyl tert-butyl ether (B) + 2-methyl-1-propanol (C) & 1.305 \\
methyl tert-butyl ether (B) + cyclohexane (C) & -0.190 \\
& 0.282 \\
& 1.580 \\
& 0.272 \\
& 0.294 \\
& 0.328 \\
& -0.174 \\
& -0.365
\end{tabular}

a Combined NIBS/Redlich-Kister curve-fit parameters are ordered as $\mathrm{S}_{0}, \mathrm{~S}_{1}$, and $\mathrm{S}_{2}$.

Table 3. Summarized Comparison between Observed Anthracene Solubilities in Ternary Methyl tert-butyl Ether + Alcohol + Cyclohexane Solvent Mixtures and Predicted Values Based upon the Combined NIMS/ Redlich-Kister Equation (Eq 2)

\begin{tabular}{|c|c|}
\hline ternary solvent mixture & $\% \operatorname{dev}^{a}$ \\
\hline $\begin{array}{l}\text { methyl tert-butyl ether (B) + 1-propanol (C) + } \\
\text { cyclohexane (D) }\end{array}$ & 1.70 \\
\hline $\begin{array}{l}\text { methyl tert-butyl ether (B) + 2-propanol (C) + } \\
\text { cyclohexane (D) }\end{array}$ & 1.66 \\
\hline $\begin{array}{l}\text { methyl tert-butyl ether }(B)+1 \text {-butanol }(C)+ \\
\text { cyclohexane (D) }\end{array}$ & 1.73 \\
\hline $\begin{array}{l}\text { methyl tert-butyl ether }(B)+2 \text {-butanol }(C)+ \\
\text { cyclohexane (D) }\end{array}$ & 1.78 \\
\hline $\begin{array}{l}\text { methyl tert-butyl ether (B) + 2-methyl-1-propanol (C) + } \\
\text { cyclohexane (D) }\end{array}$ & 1.63 \\
\hline
\end{tabular}

a Deviation $(\%)=(100 / N) \sum\left|\left[\left(x_{A}^{\text {sat }}\right)^{\text {calc }}-\left(x_{A}^{\text {sat }}\right)^{\exp }\right] /\left(x_{A}^{\text {sat }}\right)^{\exp }\right|$, where $\mathrm{N}$ corresponds to the number of data points for each ternary system. In the present study, solubilities were determined at 19 different ternary solvent compositions.

methyl tert-butyl ether. Published papers ${ }^{15-20}$ have reported the calculated $S_{\text {i }}$ parameters for anthracene dissolved in the eleven sub-binary solvent systems, as well as the measured mole fraction solubilities in 1-propanol $\left(x_{A}^{\text {sat }}=0.000591\right), 2$-propanol $\left(x_{A}^{\text {sat }}=0.000411\right)$, 1-butanol $\left(x_{A}^{\text {sat }}=0.000801\right), 2$-butanol $\left(x_{A}^{\text {sat }}=0.000585\right), 2$-methyl1-propanol $\left(x_{A}^{\text {sat }}=0.000470\right)$, cyclohexane $\left(x_{A}^{\text {sat }}=\right.$ $0.001553)$, and methyl tert-butyl ether $\left(x_{A}^{\text {sat }}=0.003050\right)$. Numerical values of the $S_{i}$ parameters have been tabulated in Table 2 for convenience. Examination of the numerical entries in Table 3 reveals that eq 2 predicts the solubility of anthracene to within an overall average absolute devia- 
532 J ournal of Chemical and Engineering Data, Vol. 45, No. 4, 2000

tion of $1.7 \%$, which is comparable to the experimental uncertainty of $\pm 1.5 \%$. For the five systems studied, eq 2 was found to provide very accurate predictions of the observed solubility behavior.

\section{Acknowledgment}

I.C. thanks the University of N orth Texas and the U.S. Department of Education for support provided under the Ronald E. McNair Postbaccalaureate Achievement Program. M.A.S. thanks the UNT Texas Academy of Math and Science (TAMS) for an undergraduate summer research fellowship.

\section{Literature Cited}

(1) Acree, W. E., J r. Polycyclic Aromatic Hydrocarbons in Pure and Binary Solvents; Volume 54 in IUPAC Solubility Data Series; Oxford University Press: Oxford, U.K., 1994.

(2) Acree, W. E., J r. Polycyclic Aromatic Hydrocarbons: Binary Nonaqueous Systems: Part 1 (Solutes A-E); Volume 58 in IUPAC Solubility Data Series; Oxford University Press: Oxford, U.K., 1995.

(3) Acree, W. E., J r. Polycyclic Aromatic Hydrocarbons: Binary Nonaqueous Systems: Part 2 (Solutes F-Z); Volume 59 in IUPAC Solubility Data Series; Oxford University Press: Oxford, U.K., 1995.

(4) Powell, J. R.; McHale, M. E. R.; Kauppila, A.-S. M.; Acree, W. E., J r.; Flanders, P. H.; Varanasi, V. G.; Campbell, S. W. Prediction of Anthracene Solubility in Alcohol + Alkane Solvent Mixtures Using Binary Alcohol + Alkane VLE Data. Comparison of Kretschmer-Wiebe and Mobile Order Models. Fluid Phase Equilib. 1994, 134, 185-200.

(5) McHale, M. E. R.; Zvaigzne, A. I.; Powell, J . R.; Kauppila, A.-S. M.; Acree, W. E., J r.; Campbell, S. W. Thermochemical Investigations of Hydrogen-Bonded Solutions. Part 9. Comparison of Mobile Order Theory and the Kretschmer-Wiebe Association Model for Predicting Pyrene Solubilities in Binary Alcohol + Alcohol Solvent Mixtures. Phys. Chem. Liq. 1996, 32, 67-87.

(6) Powell, J. R.; Coym, K. S.; Acree, W. E., J r. Solubility of Anthracene in Binary Alcohol + 2-Methoxyethyl Ether Solvent Mixtures. J . Chem. Eng. Data 1997, 42, 395-397.

(7) Acree, W. E., J r. Mathematical Representation of Thermodynamic Properties. Part 2. Derivation of the Combined Nearly Ideal Binary Solvent (NIBS)/Redlich-Kister Mathematical Representation from a Two-Body and Three-Body Interactional Mixing Model. Thermochim. Acta 1992, 198, 71-79.

(8) Acree, W. E., J r.; Zvaigzne, A. I. Thermodynamic Properties of Nonelectrolyte Solutions. Part 4. Estimation and Mathematical Representation of Solute Activity Coefficients and Solubilities in
Binary Solvents Using the NIBS and Modified Wilson Equations. Thermochim. Acta 1991, 178, 151-167.

(9) Acree, W. E., J r.; McCargar, J. W.; Zvaigzne, A. I.; Teng, I.-L. Mathematical Representation of Thermodynamic Properties. Carbazole Solubilities in Binary Alkane + Dibutyl Ether and Alkane + Tetrahydropyran Solvent Mixtures. Phys. Chem. Liq. 1991, 23, 27-35.

(10) Deng, T.; Acree, W. E., J r. Solubility of Anthracene in Ternary Propanol + 2,2,4-Trimethylpentane + Cyclohexane and Butano + 2,2,4-Trimethylpentane + Cyclohexane Solvent Mixtures. J. Chem. Eng. Data 1998, 43, 1059-1061.

(11) Deng, T.; Hernández, C. E.; Roy, L. E.; Acree, W. E., J r. Solubility of Anthracene in Ternary (Propanol + Heptane + Cyclohexane) and (Butanol + Heptane + Cyclohexane) Solvent Mixtures. J. Chem. Thermodyn. 1999, 31, 205-210.

(12) Deng, T.; Acree, W. E., J r. Solubility of Anthracene in Ternary Propanol + Butanol + Cyclohexane Solvent Mixtures. J. Chem. Eng. Data 1998, 43, 1062-1064.

(13) Deng, T.; Childress, S. D.; De Fina, K. M.; Sharp, T. L.; Acree W. E.,J r. Solubility of Anthracene in Ternary Propanol + Butanol + 2,2,4-Trimethyl pentane Solvent Mixtures. J . Chem. Eng. Data 1998, 43 (3), 1065-1067.

(14) Deng, T.; Childress, S. D.; De Fina, K. M.; Acree, W. E., J r. Solubility of Anthracene in Ternary Propanol + Butanol + Heptane Solvent Mixtures. Chem. Eng. Commun. 1999, 172, 217224.

(15) Acree, W. E., J r.; Zvaigzne, A. I.; Tucker, S. A. Thermochemical Investigations of Hydrogen-Bonded Solutions. Development of a Predictive Equation for the Solubility of Anthracene in Binary Hydrocarbon + Alcohol Mixtures Based Upon Mobile Order Theory. Fluid Phase Equilib. 1994, 92, 233-253.

(16) McHale, M. E. R.; Kauppila, A.-S. M.; Acree, W. E., J r. Solubility of Anthracene in Binary Alkane + Methyl tert-Butyl Ether Solvent Mixtures at $298.15 \mathrm{~K}$. J . Chem. Eng. Data 1996, 41, 1203-1205.

(17) Powell, J . R.; McHale, M. E. R.; Kauppila, A.-S. M.; Acree, W. E., $\mathrm{J}$ r. Solubility of Anthrcene in (Alcohol + Methyl tert-Butyl Ether) Solvents. J. Chem. Thermodyn. 1996, 28, 1215-1220.

(18) Zvaigzne, A. I.; Acree, W. E., J r. Solubility of Anthracene in Binary Alkane + 2-Butanol Solvent Mixtures. J. Chem. Eng. Data 1994 39, 114-116.

(19) Zvaigzne, A. I.; Teng, I.-L.; Martinez, E.; Trejo, J .; Acree, W. E., $\mathrm{J}$ r. Solubility of Anthracene in Binary Alkane + 1-Propanol and Alkane+ 1-Butanol Solvent Mixtures. J . Chem. Eng. Data 1993 38, 389-392.

(20) Zvaigzne, A. I.; Wolfe, J .; Acree, W. E., J r. Solubility of Anthracene in Binary Alkane + 2-Methyl-1-propanol Solvent Mixtures. J . Chem. Eng. Data 1994, 39, 541-543.

Received for review October 18, 1999. Accepted March 2, 2000.

J E990283E 